\title{
Deacidification of Soybean Oil Combining Solvent Extraction and Membrane Technology
}

\author{
M. L. Fornasero, ${ }^{1}$ R. N. Marenchino, ${ }^{1}$ and C. L. Pagliero ${ }^{1,2}$ \\ ${ }^{1}$ Departamento de Tecnología Química-UNRC-CONICET-FONCyT, Ruta Nac. 36 Km 601, 5800 Río Cuarto, Argentina \\ ${ }^{2}$ Facultad de Ingeniería, (UNRC-CONICET), Ruta Nacional No. 36 Km 601, 5800 Río Cuarto, Córdoba, Argentina \\ Correspondence should be addressed to C. L. Pagliero; cpagliero@ing.unrc.edu.ar
}

Received 13 June 2013; Accepted 12 October 2013

Academic Editor: Tao Zhang

Copyright (c) 2013 M. L. Fornasero et al. This is an open access article distributed under the Creative Commons Attribution License, which permits unrestricted use, distribution, and reproduction in any medium, provided the original work is properly cited.

\begin{abstract}
The aim of this work was to study the removal of free fatty acids (FFAs) from soybean oil, combining solvent extraction (liquidliquid) for the separation of FFAs from the oil and membrane technology to recover the solvent through nanofiltration (NF). Degummed soybean oil containing $1.05 \pm 0.10 \% \mathrm{w} / \mathrm{w}$ FFAs was deacidified by extraction with ethanol. Results obtained in the experiences of FFAs extraction from oil show that the optimal operating conditions are the following: $1.8: 1 \mathrm{w}: \mathrm{w}$ ethanol/oil ratio, 30 minutes extraction time and high speed of agitation and 30 minutes repose time after extraction at ambient temperature. As a result of these operations two phases are obtained: deacidified oil phase and ethanol phase (containing the FFAs). The oil from the first extraction is subjected to a second extraction under the same conditions, reducing the FFA concentration in oil to $0.09 \%$. Solvent recovery from the ethanol phase is performed using nanofiltration technology with a commercially available polymeric NF membrane (NF-99-HF, Alfa Laval). From the analysis of the results we can conclude that the optimal operating conditions are pressure of $20 \mathrm{bar}$ and temperature of $35^{\circ} \mathrm{C}$, allowing better separation performance: permeate flux of $28.3 \mathrm{~L} / \mathrm{m}^{2} \cdot \mathrm{h}$ and FFA retention of $70 \%$.
\end{abstract}

\section{Introduction}

Oilseeds are one of the most common sources of edible vegetable oils and fats. The process of obtaining oil from them consists in preparing the seed and then extracting the oil (by means of solvent extraction or crushing). After that, the crude oil obtained is refined; these stages are degumming, deacidification, bleaching, and finally deodorizing. These industrial processes are carried out with conventional technology and consume a great amount of energy, such as electricity, natural gas, or liquid fuel; this results in considerable oil loss and high content of effluents [1,2].

In the oils and fats processing industry, deacidification (the removal of free fatty acids or FFAs) is important, not only for consumer acceptance, but also for its high economic impact over production. Conventional methods for the removal of FFAs from oils consist in chemical and physical deacidification. The chemical process has disadvantages such as high energy consumption, thermal damage to the oil, high discharge of effluents, and oil loss [3]. In the physical process, the FFAs are distilled; this method offers the following advantages over chemical refining: improvement of product quality, the elimination of soapstock, and effluent reduction; its disadvantages are that the requirements for pretreatment of crude oil are stricter; the most important is that the phosphorus and iron levels should be low. The iron concentration has to be lower than $0.2 \mathrm{ppm}$, because this can cause the darkening of oil during distillation and reduce its oxidative capacity [4]. New technologies are being analyzed as an alternative to conventional deacidification process.

Separation technology using membranes has evolved quickly in the last two decades. This has allowed scientists to isolate, purify, and separate very complex mixtures. Due to its high energetic efficiency, this separation technology is being utilized by industries for the effluents treatment, fruit and vegetable juice processing, products processing, and protein recovery and purification, among other uses [5].

The main reason for the use of membrane technology in the vegetable oil industry is its advantages compared to 
conventional processes, since it allows the selective separation of molecules according to the needs in each stage; it minimizes thermal damage and reduces the consumes energy and effluent production. Because of these advantages, its application in different stages of the production of edible oils is under constant research and expansion [3, 6-12]. The disadvantages this technology presents, which currently limit its industrial use, are related to poor membrane stability in relation to organic solvents and low permeate fluxes. This is why the new improved membranes elaboration is under constant research and development [13].

Crude vegetable oils contain FFAs together with triglycerides (oil). The deacidification process involves the removal of FFAs from crude oil to provide more stability and to make it more acceptable for consumers. This stage is the most delicate and difficult one in the refining process, since it determines final product quality; besides, it is the stage with the highest economic impact on the refining process. Conventional chemical and physical methods with which deacidification is industrially performed have already been widely studied [14]. Due to the disadvantages that they present, the study of innovative methods becomes interesting and attractive. Different researchers have reported on deacidification utilizing liquid-liquid extraction and dense and porous membranes [2, 15-19]. Main drawback in FFAs membrane separation refers to the small difference between the molecular weight of the triglycerides $(800 \mathrm{Da})$ and the FFAs (300 Da). Bhosle and Subramanian [16] report that the main limitation of FFA separation by membrane technology is its low selectivity due to the small difference in molecular weight and low permeate flux incomparable with industrial needs.

The aim of the present work was to study the removal of FFAs from soybean oil by liquid-liquid extraction and the solvent recovery by nanofiltration.

\section{Materials and Methods}

2.1. Materials. The raw material used was degummed soybean oil from regional industry (OLCA S.A.I.C, General Cabrera, Argentina). The FFA extraction experiments were performed using analytical grade ethanol, isopropanol, and acetone. A commercially available polymeric composite nanofiltration membrane called NF-99-HF was used (Alfa Laval, Buenos Aires, Argentina). This is designed to reject organics with molecular weight above $200 \mathrm{Da}$. The membrane elements are based on a polyamide type thin film composite on polyester membrane.

Ethanol was selected instead of methanol, because it has low toxicity, is easily recoverable, and has good selectivity and distribution coefficient for FFAs, along with minimum losses of nutraceutical component.

2.2. Methods. The FFAs liquid-liquid extraction from oil was performed in two stages: the first one using the degummed soybean oil and the second one using the portion of FFAspoor oil from the first stage. There was a varied ratio of solvent/oil (1:1 and 1.8:1 w:w) and rest times (24 hour and
30 minutes) remained constant: speed stirring (700 rpm), time stirring (30 minutes), and temperature $\left(20 \pm 2^{\circ} \mathrm{C}\right)$. The FFAs-rich solvent extracts from two extraction stages were combined and used in the nanofiltration experiments.

The nanofiltration setup (Figure 1) consists of a $300 \mathrm{~mL}$ capacity dead-end cell equipped with a magnetic stirrer (HP 4750 cell, Sterlitech, USA), a hot plate with temperature control (FA 5 PIM MR, Thorbell, Santa Fé, Argentina), and temperature and pressure sensors, as can be observed in Figure 1. Solvent permeability was determined previous to the separating experiences. After that, the mixture solvent/FFAs permeation experience was conducted for two hours. Transmembrane pressure $(\Delta P)$ varied in the 5-20 bar range and system temperature $(T)$ between $23-35^{\circ} \mathrm{C}$. Feed FFAs concentration $\left(C_{a}\right)$ was constant at $0.20 \pm 0.03 \% \mathrm{w} / \mathrm{w}$ of oleic acid.

Permeate flux was evaluated from

$$
J=\frac{V}{t \times A},
$$

where $J$ is the volumetric permeation flux $\left(\mathrm{L} / \mathrm{m}^{2} \cdot \mathrm{h}\right), V$ is the permeate volume (L), $t$ the time $(\mathrm{h})$, and $A$ is the filter area $\left(\mathrm{m}^{2}\right)$.

The permeate flux at steady state $J^{*}$ is the volumetric permeate flux $\left(\mathrm{L} / \mathrm{m}^{2} \cdot \mathrm{h}\right)$ evaluated at 120 minutes of permeation experience, in pure solvent and in the mixture solvent-free fatty acids.

The FFAs retention factor $(R)$ was calculated as

$$
R \%=\left(\frac{C_{a}-C_{p}}{C_{a}}\right) \times 100,
$$

where $C_{a}$ and $C_{p}$ are free fatty acid concentrations in the feed and permeate, respectively.

The membrane cleaning procedure consisted in washing the membrane with an enzymatic detergent aqueous solution at ambient temperature for 15 minutes, rinsing it with distilled water, then permeating water during 30 minutes, and finally permeating the pure solvent. If necessary, the cleaning procedure was repeated until the hydrodynamic permeability of cleaned membrane was similar to that of original membrane (95-100\%).

2.3. Analytic Methods. The FFA concentration was determined according to the AOCS Ca 5a-40 method, with an automatic titrator Titrino plus 848 (Metrohm, Switzerland) with Solvotrode electrode for titration in nonaqueous media Solvotrode (Metrohm, Switzerland). The FFA concentration was expressed as percent oleic acid (\% w/w oleic acid).

\section{Results and Discussion}

3.1. FFAs Extraction. Degummed soybean oil deacidification experiences, with an FFA concentration of $1.05 \pm 0.10 \%$ w/w oleic acid, were performed with the following solvents: ethanol, isopropanol, and acetone. It was observed that isopropanol and acetone dissolved high contents of oil in addition to FFAs, which did not allow an adequate separation 


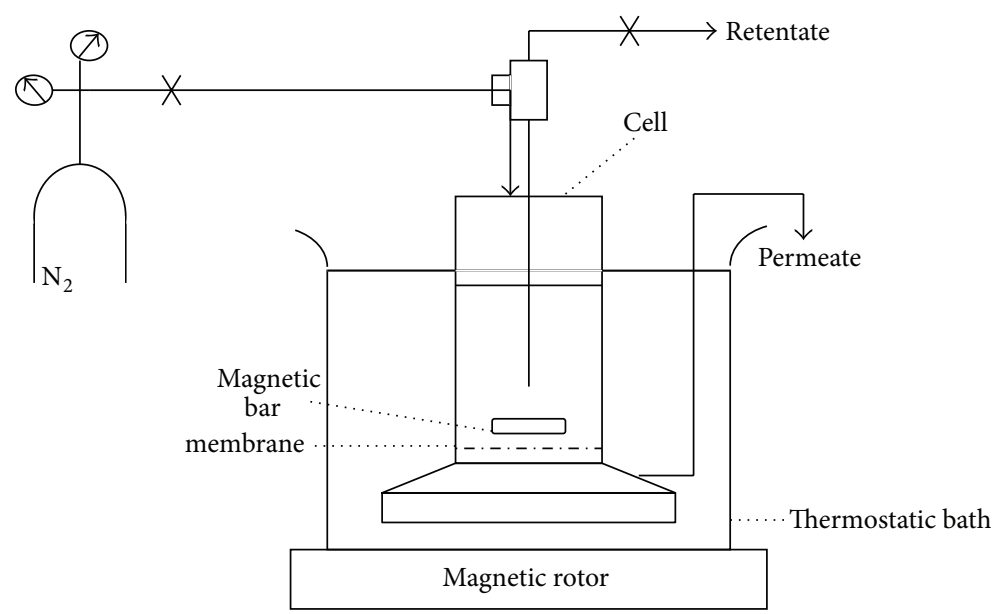

FIgURE 1: Schematic diagram of dead-end cell.

TABLE 1: Experimental results of extraction of FFAs from soybean oil.

\begin{tabular}{lccc}
\hline $\begin{array}{l}\text { Ethanol/oil ratio } \\
\text { (by weight) }\end{array}$ & \% FFAs feed & $\begin{array}{c}\text { \% FFAs ethanol } \\
\text { phase }\end{array}$ & $\begin{array}{c}\text { \% FFAs oil } \\
\text { phase }\end{array}$ \\
\hline & Experience 1 & & \\
$1: 1$ (First stage) & 1.10 & 0.58 & 0.51 \\
$1: 1$ (Second stage) & 0.51 & 0.28 & 0.24 \\
\hline & Experience 2 & & \\
$1: 1$ (First stage) & 1.17 & 0.62 & 0.54 \\
$1: 1$ (Second stage) & 0.54 & 0.24 & 0.36 \\
\hline & Experience 3 & & \\
$1.8: 1$ (First stage) & 0.98 & 0.33 & 0.23 \\
$1.8: 1$ (Second stage) & 0.23 & 0.10 & 0.07 \\
\hline & Experience 4 & & \\
$1.8: 1$ (First stage) & 0.94 & 0.38 & 0.35 \\
$1.8: 1$ (Second stage) & 0.35 & 0.11 & 0.11 \\
\hline
\end{tabular}

of the phases. As a result, ethanol was selected as the solvent used for extraction.

Different tests were performed with the aim of obtaining the best operating conditions during the phase of extraction of FFAs from oil. In relation to phase separation time, trials were conducted with 30 minutes and 24 hours of rest time. With respect to the ethanol/oil ratio, the relations $1: 1 \mathrm{~W}: \mathrm{W}$ and $1.8: 1 \mathrm{w}: \mathrm{w}$ were used in both extraction stages. Table 1 shows the FFA concentration feed oil and of each of the portions obtained in the first and second extraction stages. The best FFAs separating conditions from soybean oil were obtained for 30 minutes separation time and an 1.8:1 w: w ethanol/oil ratio in both extraction steps; obtaining oil with an acidity of $0.09 \pm 0.10 \% \mathrm{w} / \mathrm{w}$ oleic acid means the removal of $75 \%$ of FFAs in the oil. On the other hand, in the separation performed using the ratio $1: 1 \mathrm{w}: \mathrm{w}$, ethanol/oil was obtained oil with an acidity of $0.30 \pm 0.08 \% \mathrm{w} / \mathrm{w}$ oleic acid, being the FFA reduction in the oil of $48 \%$ in the two extraction stages.

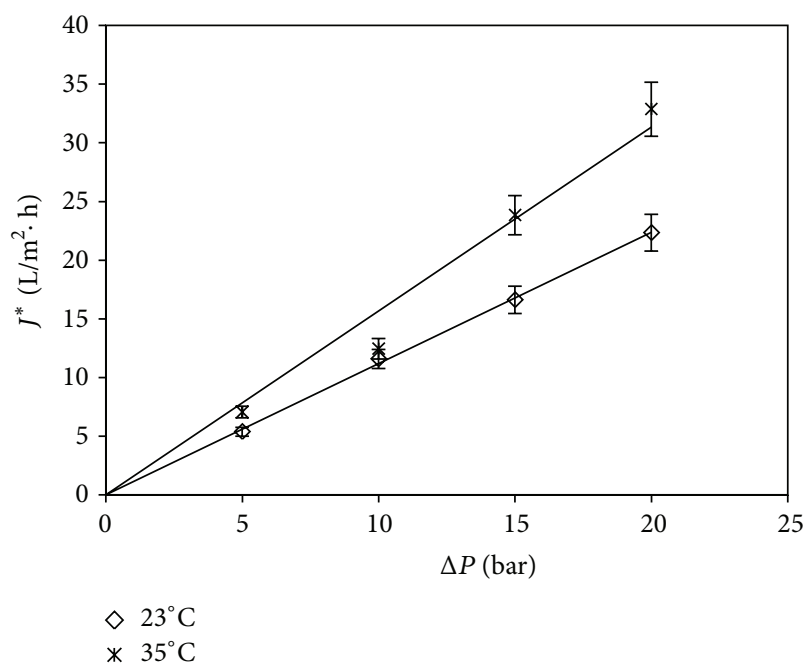

FIGURE 2: Effect of transmembrane on ethanol permeate flux $\left(J^{*}\right)$ to 23 and $35^{\circ} \mathrm{C}$.

3.2. Ethanol Recovery by Nanofiltration. Ethanol permeability was determined from the slope of the curve that results when representing permeate flux values at steady state $\left(J^{*}\right)$ in relation to the transmembrane pressure applied $(\Delta P)$ for the two temperatures analyzed. As shown in Figure 2, there is a linear increase in permeate flux with transmembrane pressure for the range of 5 to 20 bar. For this reason we can consider that there is no membrane compaction at this range of pressure. The ethanol permeability values obtained were $1.12 \mathrm{~L} / \mathrm{m}^{2} \cdot \mathrm{h} \cdot \operatorname{bar}\left(r^{2}: 0.99\right)$ for $23^{\circ} \mathrm{C}$ and $1.57 \mathrm{~L} / \mathrm{m}^{2} \cdot \mathrm{h} \cdot \operatorname{bar}\left(r^{2}\right.$ : $0.96)$ for $35^{\circ} \mathrm{C}$. It can be observed that ethanol permeability increases with an increase in temperature, because of a decrease in the ethanol viscosity and an increase in the polymeric chains mobility, which brings about an increase in macromolecule diffusion [20].

Figure 3 shows how permeate flux varies as a function of time during the experiences of ethanol recovery from FFAs/ethanol mixtures for two operating temperatures 


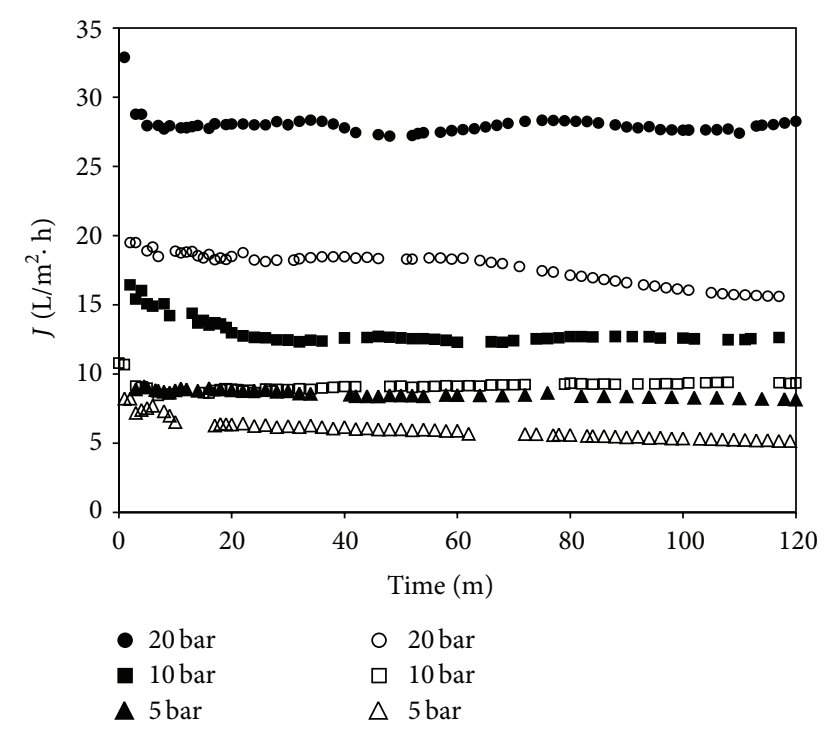

Figure 3: Permeate flux $(J)$ as a function of time during the recovery ethanol experiences to $\Delta P$ 5-20 bar and $24^{\circ} \mathrm{C}$ (empty symbols) and $35^{\circ} \mathrm{C}$ (filled symbols).

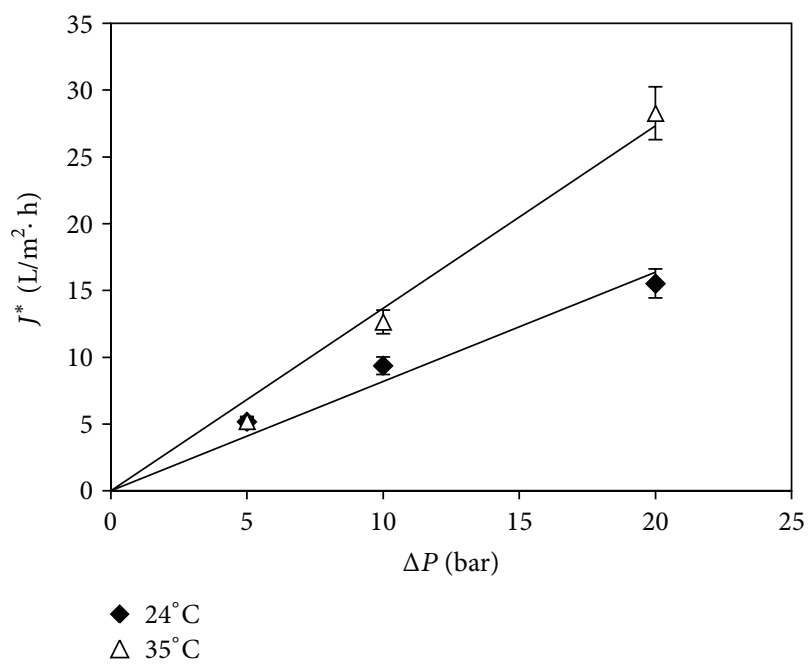

FIGURE 4: Effect of transmembrane pressure on permeate flux $\left(J^{*}\right)$ to 24 and $35^{\circ} \mathrm{C}$.

$\left(24\right.$ and $35^{\circ} \mathrm{C}$ ), the transmembrane pressure range analyzed (5-20 bar), and feed FFAs concentration of $0.20 \pm 0.03 \%$ $\mathrm{w} / \mathrm{w}$. At the beginning of the experiences a steady decrease of permeate flux (5-20\%) can be observed. For periods over 30 minutes permeate flux does not vary until it is practically constant (pseudo-steady state). This behavior can be attributed to the polarization by concentration phenomenon.

Figure 4 shows the effects of transmembrane pressure on permeates flux at steady state at a temperature of 24 and $35^{\circ} \mathrm{C}$. Permeate flux increases linearly as pressure increases. This indicates that the pressure range used in this work is the pressure that controls the permeate flux and that the effects of fouling are minimal. Permeabilities obtained at 24 and $35^{\circ} \mathrm{C}$
TABLE 2: Flux and FFAs retention $(R \%)$ during recovery ethanol using the NF membrane.

\begin{tabular}{cccccc}
\hline$T\left({ }^{\circ} \mathrm{C}\right)$ & $\Delta P($ bar $)$ & $\begin{array}{c}C_{a} \text { FFAs } \\
(\% \mathrm{w} / \mathrm{w})\end{array}$ & $\begin{array}{c}C_{p} \mathrm{FFAs} \\
(\% \mathrm{w} / \mathrm{w})\end{array}$ & $R \%$ & $J^{*}\left(\mathrm{~L} / \mathrm{m}^{2} \cdot \mathrm{h}\right)$ \\
\hline \multirow{3}{*}{24} & 20 & 0.17 & 0.05 & 72 & $15.5 \pm 1.1$ \\
& 10 & 0.20 & 0.05 & 76 & $9.4 \pm 0.7$ \\
& 5 & 0.19 & 0.03 & 87 & $5.2 \pm 0.4$ \\
\hline \multirow{3}{*}{35} & 20 & 0.21 & 0.06 & 70 & $28.3 \pm 2.0$ \\
& 10 & 0.20 & 0.05 & 76 & $12.6 \pm 0.9$ \\
& 5 & 0.25 & 0.06 & 75 & $8.2 \pm 0.6$ \\
\hline
\end{tabular}

are $0.82 \mathrm{~L} / \mathrm{m}^{2} \cdot h \cdot \operatorname{bar}\left(r^{2}: 0.93\right)$ and $1.40 \mathrm{~L} / \mathrm{m}^{2} \cdot h \cdot \operatorname{bar}\left(r^{2}: 0.98\right)$, respectively.

Table 2 shows the results obtained from permeation experiences of FFAs/ethanol mixtures for the different operating conditions used. The retention percentages of FFAs are not significantly affected by the operational variables ( $T$ and $\Delta P$ ), ranging between 70 and $87 \%$ in the range analyzed. While, in general, the rejection data show a small decrease with pressure increase; these variations may be due to the fact that higher pressure can force the FFA molecules to permeate through the membrane pores [21].

\section{Conclusions}

The results of this study show that membrane technology combined with solvent extraction is effective in the soybean oil deacidification. From the analysis of the results in the extraction of the oil FFAs, we can conclude that the best condition corresponds to the separation time of 30 minutes and ethanol/oil ratio of $1.8: 1 \mathrm{w}: \mathrm{w}$ for the two stages of extraction. A separation greater than $20 \%$ FFAs from oil when varying the ethanol content from 1 to 1.8 was achieved, not observing variations in the rest time. From the analysis of the results of the FFAs/ethanol mixture nanofiltration experiences it can be concluded that permeate flux increases with increasing transmembrane pressure. This behaviour is characteristic of the filtration systems that have pressure difference as a driving force. An analysis of the effect of temperature reveals that permeate flow increases when temperature rises. This can be attributed to the fact that the viscosity of the fluid decreases with increasing temperature, which causes an increase in the permeate flux for a given pressure difference. The best operating conditions are $20 \mathrm{bar}$ and $35^{\circ} \mathrm{C}$, obtaining the best permeoselectivity: $J^{*}=28.3 \mathrm{~L} / \mathrm{m}^{2} \cdot \mathrm{h}$ and retention of $70 \%$. Similar results were obtained by Raman et al. [15]; these authors used several commercial NF membranes, methanol as solvent, and solution in methanol FFA model (the best resulted in rejection of $90 \%$ and flux of $25 \mathrm{~L} / \mathrm{m}^{2} \cdot \mathrm{h}$ ).

When the permeate flux varied as a function of time at the beginning of the experiences, a steady decrease of permeate flux (5-20\%) can be observed. For periods over $t=30 \mathrm{~min}$ permeate flux does not vary until it is practically constant (pseudo-steady state). This behaviour can be attributed to the polarization by concentration phenomenon. 


\section{Acknowledgments}

The authors acknowledge the National Research Council of Argentina (CONICET) and National Agency for Scientific Promotion (ANPCyT) for their financial support.

\section{References}

[1] R. A. Carr, "Degumming and refining practices in the U.S," Journal of the American Oil Chemists' Society, vol. 53, pp. 347352, 1976.

[2] V. Kale, S. P. R. Katikaneni, and M. Cheryan, "Deacidifying rice bran oil by solvent extraction and membrane technology," Journal of the American Oil Chemists' Society, vol. 76, no. 6, pp. 723-727, 1999.

[3] S. S. Koseoglu, "Membrane technology for edible oil refining," Oils \& Fats International, vol. 5, pp. 16-21, 1991.

[4] R. Subramanian, M. Nakajima, K. S. M. S. Raghavarao, and T. Kimura, "Processing vegetable oils using nonporous denser polymeric composite membranes," Journal of the American Oil Chemists' Society, vol. 81, no. 4, pp. 313-322, 2004.

[5] M. Cheryan, Ultrafiltration Handbook, Technomic Publishing, Lancaster, Pa, USA, 1986.

[6] J. B. Snape and M. Nakajima, "Processing of agricultural fats and oils using membrane technology," Journal of Food Engineering, vol. 30, no. 1-2, pp. 1-41, 1996.

[7] L. P. Raman, N. Rajagopaln, and M. Cheryan, "Membrane technology," Oils \& Fats International, vol. 6, no. 10, pp. 28-39, 1994.

[8] F. Cuperus and J. Derksen, "Applications of membrane technology in the processing of vegetable oils and derivatives," Lipid Technology, pp. 101-107, 1995.

[9] C. Pagliero, N. Ochoa, J. Marchese, and M. Mattea, "Vegetable oil degumming with polyimide and polyvinylidenefluoride ultrafiltration membranes," Journal of Chemical Technology and Biotechnology, vol. 79, no. 2, pp. 148-152, 2004.

[10] C. Pagliero, M. Mattea, N. Ochoa, and J. Marchese, "Fouling of polymeric membranes during degumming of crude sunflower and soybean oil," Journal of Food Engineering, vol. 78, no. 1, pp. 194-197, 2007.

[11] C. de Morais Coutinho, M. C. Chiu, R. C. Basso, A. P. B. Ribeiro, L. A. G. Gonçalves, and L. A. Viotto, "State of art of the application of membrane technology to vegetable oils: a review," Food Research International, vol. 42, no. 5-6, pp. 536-550, 2009.

[12] A. R. Ladhe and N. S. Krishna Kumar, "Application of membrane technology in vegetable oil processing," in Membrane Technology, pp. 63-78, 2010.

[13] M. de Souza Araki, C. de Morais Coutinho, L. A. G. Gonçalves, and L. A. Viotto, "Solvent permeability in commercial ultrafiltration polymeric membranes and evaluation of the structural and chemical stability towards hexane," Separation and Purification Technology, vol. 71, no. 1, pp. 13-21, 2010.

[14] A. Moustafa, "Producción de aceite de soja de alta calidad," Grasas y Aceites, vol. 46, pp. 366-368, 1995.

[15] L. P. Raman, M. Cheryan, and N. Rajagopalan, "Deacidification of soybean oil by membrane technology," Journal of the American Oil Chemists' Society, vol. 73, no. 2, pp. 219-224, 1996.

[16] B. M. Bhosle and R. Subramanian, "New approaches in deacidification of edible oils-a review," Journal of Food Engineering, vol. 69, no. 4, pp. 481-494, 2005.
[17] I. Sereewatthanawut, I. I. R. Baptista, A. T. Boam, A. Hodgson, and A. G. Livingston, "Nanofiltration process for the nutritional enrichment and refining of rice bran oil," Journal of Food Engineering, vol. 102, no. 1, pp. 16-24, 2011.

[18] Y. P. C. Rao, R. Ravi, and S. Khatoon, "Deacidification of coconut oil by membrane filtration," Food and Bioprocess Technology, vol. 6, no. 2, pp. 498-508, 2013.

[19] L. Firman, N. Ochoa, J. Marchese, and C. L. Pagliero, "Deacidification and solvent recovery of soybean oil by nanofiltration membranes," Journal of Membrane Science, vol. 431, pp. 187-196, 2013.

[20] R. Rautenbach and R. Albrecht, Membrane Processes, John Wiley \& Sons, Chichester, NH, USA, 1989.

[21] A. P. Ribeiro, J. M. de Moura, L. A. Gonçalves, J. C. Petrus, and L. A. Viotto, "Solvent recovery from soybean oil/hexane miscella by polymeric membranes," Journal of Membrane Science, vol. 282, no. 1-2, pp. 328-336, 2006. 

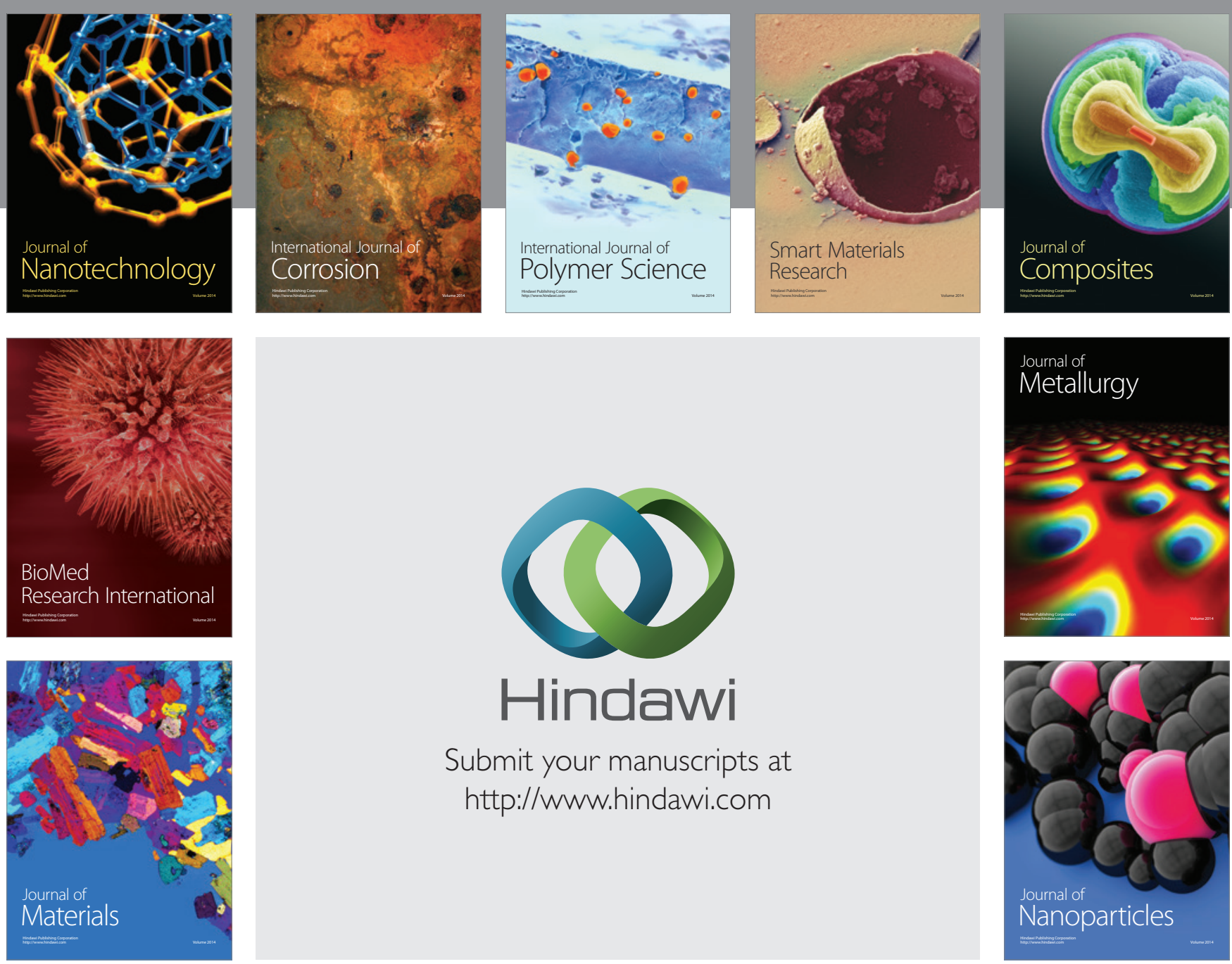

Submit your manuscripts at http://www.hindawi.com
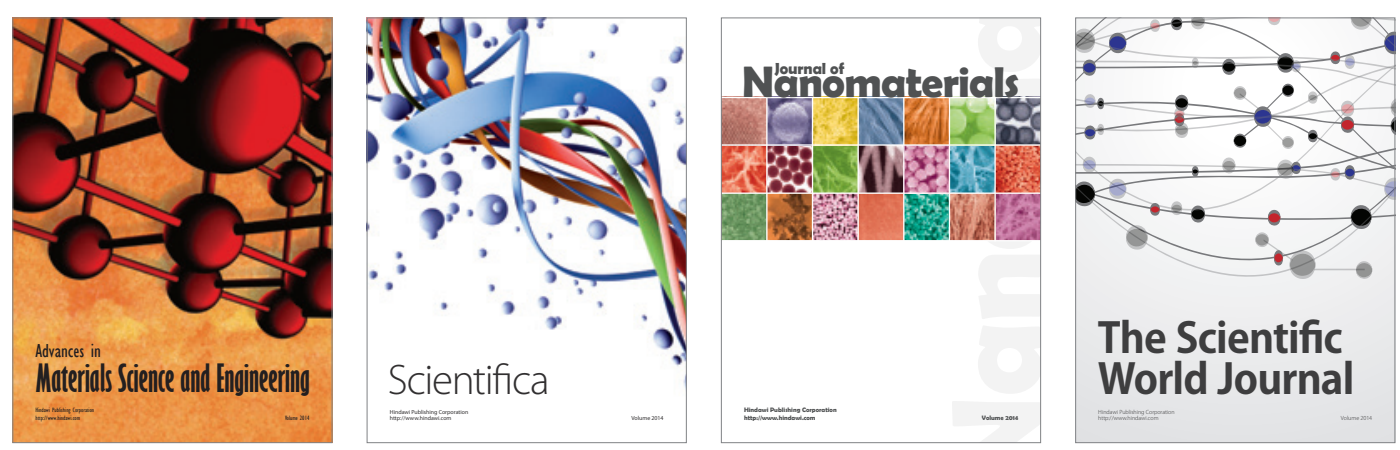

\section{The Scientific World Journal}
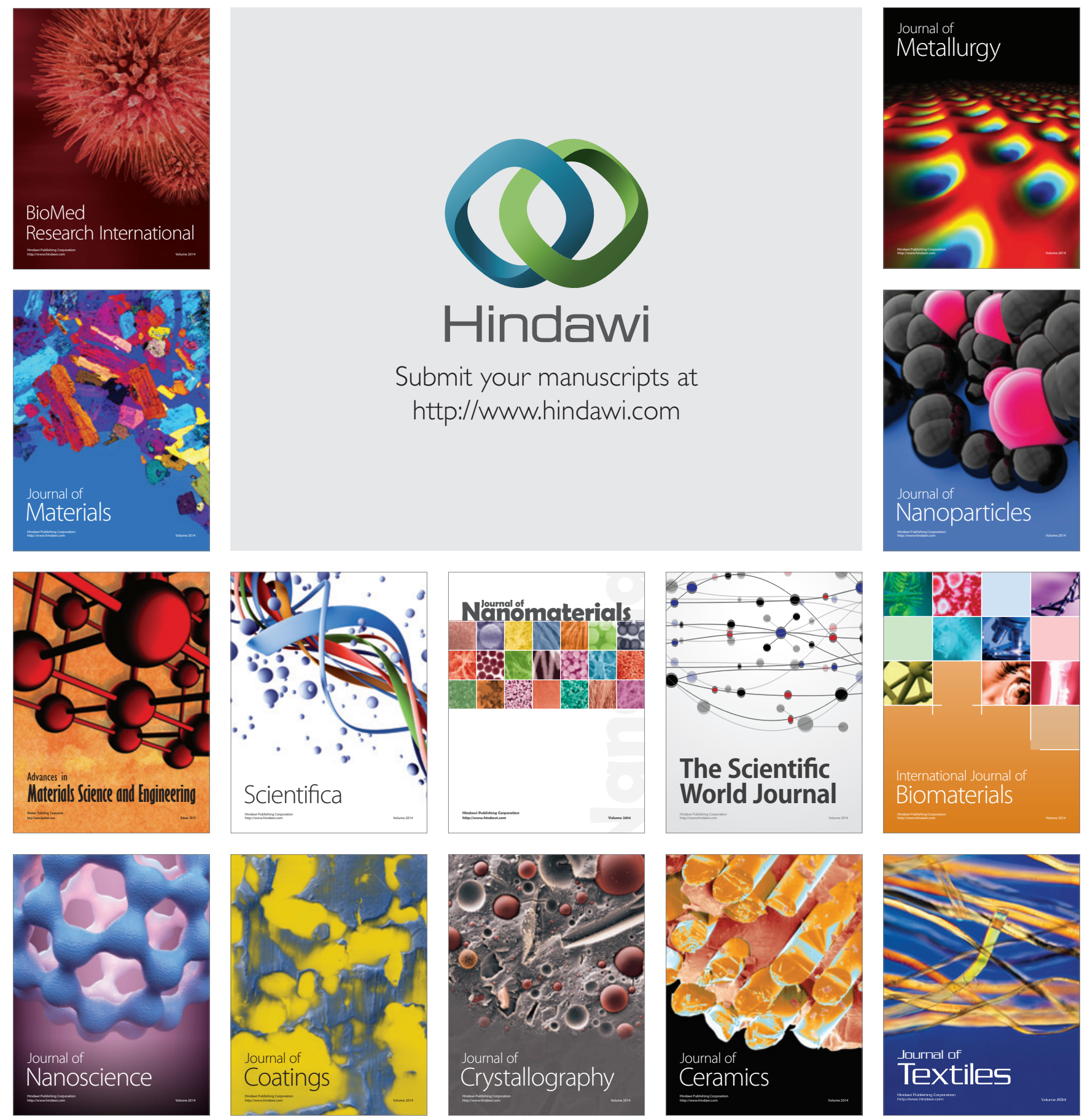